\title{
The Use of Electronic Dictionaries in EFL Classroom
}

\author{
Huibin Zheng $^{1 *} \&$ Xiaoli Wang ${ }^{1}$ \\ ${ }^{1}$ English Language Center, Shantou University, Shantou, China \\ *Huibin Zheng, E-mail: zhenghb@stu.edu.cn
}

\begin{abstract}
Today's dictionaries have more information and are easier to access and to understand than ever before. And, with the advent of electronic formats, space is no longer the problem it was. Electronic dictionaries have become more and more attractive, accepted and popular to EFL learners at different levels, using electronic dictionaries in EFL classroom has gradually become an alternative to many. As for teachers, helping students tap into electronic dictionaries effectively is one of the best ways to help them become independent, lifelong language learners. In this essay, the functionality of electronic dictionaries and reasons why they are popular in EFL class will be introduced. Also, some of the current issues related to the integration of electronic dictionaries into EFL instruction and learning will be identified and discussed. The author's views towards this topic will be presented as well, based on the observation and reflection of using electronic dictionaries in EFL classes at a Chinese university.
\end{abstract}

\section{Keywords}

electronic dictionary, English as a Foreign Language (EFL), English as a Second Language (ESL)

\section{Introduction}

For language instructors and learners to participate in an increasingly digital world, they will need to use technology via English to meet their educational and personal needs. Not long ago, electronic dictionaries began to enter EFL (English as a Foreign Language) classrooms and became more and more popular among Chinese university students. In addition to reading dictionaries, students can also hear pronunciations, watch illustrative videos and use other functionality (links, cross-references, etc.) Although electronic dictionaries have massive amount of information and fast search, teachers and researchers still need to consider other factors in the environment that could have an impact on student outcomes. This is not surprising_although electronic dictionaries can be used as a tool in the same ways that paper dictionaries can, they are capable of more than such tools, and both learners and teachers must understand both the advantages and liabilities of using electronic dictionaries. Therefore, some researchers consider electronic dictionaries as valuable tools in EFL instruction and learning, while others view the integration of electronic dictionaries into university EFL class with a number of concerns, many of which remain unresolved.

In this essay, the unique functionality of electronic dictionaries will be introduced, as well as some 
reasons why they are popular in EFL class. Also, some of the current issues related to the integration of electronic dictionaries into EFL instruction and learning will be identified and discussed. The author's views towards this topic will be presented as well, based on the observation and reflection of using electronic dictionaries in EFL classes at a Chinese university.

\section{Background}

\subsection{Vocabulary Acquisition and Dictionary}

According to Summers (1988), vocabulary acquisition is considered to play an very important part in foreign language learning. If language learners do not have wide enough range of vocabulary and vocabulary usage, it may lead to them being confused in different language tasks, especially in reading and listening (Luppescu \& Day, 1993). However, by the means of using a dictionary, students are found to be more willingly to learn new and unfamiliar words by themselves, although it seems some specific trainings are needed on how to use dictionaries (Gonzalez, 1999). Furthermore, vocabulary acquisition is discovered to be improved for students who consult dictionaries for new vocabulary in their reading and listening activities (Hulstijn et al., 1996).

\subsection{Print vs Electronic Dictionary}

Dictionaries are considered to be very useful language learning tools. Language learners should be exposed to extensive reading and listening. Thus, dictionaries are simple tools which help language learners to check pronunciation and spelling and of unknown words. More importantly, they give meanings to words which have not been understood by the user. Also, in learner's dictionaries that most EFL students use, they give the information on how a word is used in a sentence. They are used to help language learner to check the meanings of words or phrases that they do not understand, as well as the usages. Dictionaries are very practical for both teachers and students in and out of class. What EFL teachers should teach their students are the different ways of using a dictionary, how to find words and also what other relevant information students can find in it. Students need to realize that dictionaries can become their study companions at home or away when their teachers are not there.

While significant digital divides of access still exist, many of today's university students have grown up in a world in which they assume they are always connected to the Internet and can communicate with their peers (and perhaps even teachers) via Web-based social networking applications. Set against the landscape of an increasingly mobile, wireless and networked society (Castells, 2000), these new technologies are bringing with them new forms of electronic literacies (Lankshear \& Knobel, 2003; Warschauer, 1999). Though there is still some way to go before such technologies have achieved a "normalized" state, as Bax (2003) argues, language learners and teachers are increasingly using new technologies for writing on a computer, searching and reading for information on the Internet, communicating via email and text message, doing language tests, and meeting with native and non-native speaking peers and collaborators with the aid of web camera. Among all these new technologies, electronic dictionaries are a particularly popular tool for EFL learners in China (Chen, 
2007).

An electronic dictionary is a portable electronic device that serves as the digital form of any kind of dictionary. Available in a number of forms (dedicated handheld device, apps on mobile devices, CD-ROMs or DVD-ROMs and online products), electronic dictionaries range in function from general single-language dictionaries to very specific, terminology-based dictionaries for medical, legal, and other professional languages. As technology has advanced, the number of features that are available in electronic dictionaries has also increased. Many of them are equipped with text-to-speech and speech-to-text capabilities, interactive vocabulary games, vocabulary journal, data transportation and internet access. Most recently, electronic dictionaries have become available on mobile devices such as smartphones and tablet computers. There are a number of differences exist between the traditional paper dictionary and the electronic ones. Because of the function of data transportation and internet access, the number of vocabulary items included in electronic dictionaries exceeds the number in the paper ones. Also, there are some unique features that cannot be found in the paper dictionary, for example, interactive learning functions such as vocabulary games, speech features, and reference book. Clearly, the electronic dictionary is faster in search speed, lighter in weight, smaller in size and more mobile than the paper one.

\subsection{Use of Electronic Dictionary}

With the unique features, the use of electronic dictionary causes some problems as well. Electronic dictionaries can prevent students guessing skills and contextualized thinking in vocabulary acquisition. EFL learners tend to separate words from the context and they do not realize that using the context would help them understand the meanings. With the fast-speed search functionality of electronic dictionaries, they would immediately look up the meanings of all unknown words and phrases in a sentence while actually getting the meanings of one or two key words plus guessing meanings from context would serve the purpose in the same way.

Moreover, electronic dictionaries can cause distraction. It often takes place when students use electronic dictionaries in the classrooms. It happens when students are trying to look up the meaning of new words. They tend to go straight ahead and look up every unknown word they come across because it is easy and fast for them to get the meanings and other relevant information from electronic dictionaries. However, according to Peters' (2007) research, those words are not related to the focus of the lesson in most of the cases. As a result, students might ignore what the teacher is saying and pay little attention to the lesson.

Electronic dictionaries can also be very disturbing when students use them in the classroom. The voice of electronic dictionaries that suddenly occurs in class could be very annoying or surprising to the teacher and the students who are busy doing their work. The using of electronic dictionary by one student could affect the rest of students because they would be easily hearing pronunciations and explanations of irrelevant words while their teacher is teaching, which could discourage them from focusing on the lesson. As a result, it might be a great disturbance for both teachers and students during 
the learning process. Additionally, there are also arguments of whether to trust the correctness of pronunciation and explanation in electronic dictionaries because some of them are not accurate due to various reasons. This could also cause students to be confused when they judge over the teacher's correct pronunciation or provided meaning.

\section{Literature Review}

Electronic dictionaries are particularly popular with EFL students especially in South and East Asian countries. It is believed by Stinling (2005) that the exclusive preference for electronic dictionaries by EFL students in or from eastern Asian countries is because of the similar educational systems, which emphasis more on accuracy rather than guessing and rist-taking in EFL teaching and learning. Midlane (2005) conducted an international online survey of EFL learners' use of electronic dictionaries in classroom. It is stated that compared to other parts of the world, students from eastern Asian countries were more willingly to use electronic dictionaries in class. In Japan, a great number of EFL learners chose to use electronic dictionaries (Kobayashi, 2008). Bower and McMillan's survey (2007) found that $96 \%$ of the students owned electronic dictionaries and most of them used electronic dictionaries frequently in English learning. In another study, Perry (2003) found that compare to the usage of paper dictionaries, $83 \%$ of the students said they would prefer to use electronic dictionaries. Similarly, researchers in China also proved the popularity of electronic dictionaries among Chinese EFL learners. In a study which is conducted earlier on the use of electronic dictionaries, Tang (1997) noticed that among 254 Chinese immigrant or international students in Vancouver, $87 \%$ of them had electronic dictionaries. In a survey conducted by Deng (2005), 70\% of 80 Chinese college students were users of electronic dictionary. In Stirling's (2005) interview in a UK language school, most of the 11 EFL students were in favor of electronic dictionary. Boommoh and Nesi's (2008) questionnaire survey reported that although the majority of Thai students (938 out of 1121) own learner's dictionaries in book form, only 102 and 46 students separately sated that they often used their paper dictionaries to support their reading and writing. On the contrary, 456 students who claimed owing electronic dictionaries were found to use them to support their language learning. 435 students reported using electronic dictionaries for reading and 412 for writing. Another statistics which may arrest researchers' attention is that the number of students (818 students) who stated they want to by electronic dictionaries in the future is far more than the number of students (117 students) who stated they want to buy learner's dictionaries in book form. Students obviously prefer electronic dictionaries to paper dictionaries. Midlane (2005, p. 125) pointed out that the growth in electronic use is a bottom-up movement. It is led by students, not by teachers or lexicographers. Moreover, the widely use of electronic dictionaries may change the model of classroom learning to a certain extent.

According to different researchers, finding or checking the meaning(s) of new vocabulary or phrases is the main purpose of using electronic dictionaries (Taylor \& Chan, 1994; Weschler \& Pitts, 2000; Wang, 2003; Deng, 2006). Weschlet and Pitts (2000) called the trend of using electronic dictionaries for such 
receptive tasks the "absorbing sponge syndrome". They also found this sponge was "rarely squeezed" because students rarely used electronic dictionaries for production. According to Kent's (2001) study in a Korean university, $69 \%$ of the students said they mostly used electronic dictionaries in reading. At the same time, electronic dictionaries were least used in listening or speaking. It is discussed that the dominant role of electronic dictionaries in vocabulary learning may result from students' belief that vocabulary is "at the heart of mastering a foreign language" (Tang, 1997). More than half of the respondents in Kent's (2001) study stated audio pronunciation was the most useful function of electronic dictionaries. However, language learners in other researches were discovered to make little use of audio pronunciation, in regard to the use of it within electronic dictionaries (Weschler \& Pitts, 2000; Wang, 2003; Bower \& McMillan, 2007).

Some researches reveal that electronic dictionaries do have positive effects on EFL learning. In a study conducted by Korat and Shamir (2006), they revealed that students' use of electronic dictionaries demonstrated a positive effect on language learning in a read-with-dictionary task compare to a read-only task. In another study conducted among university students in Korea, researchers found that teachers' guidance on how to use electronic dictionaries has an important impact on students' positive attitude towards the use of them (Park, 2006). It is also revealed that the deficiency of dictionary skills among foundation and intermediate level EFL learners may block their way from finding the meanings of culturally related or terminological words and phrases. Electronic dictionaries that can access to the Internet are found to be more suitable for beginning EFL learners, because compare to paper dictionaries, there is no limitations of space and linear search in electronic dictionaries (McAlpine \& Myles, 2003).

Nevertheless, by comparing the use of paper dictionary, some researchers found the use of electronic dictionary does not have advantages. In Koyama and Takeuchi's (2003) study in a Japanese university, after they compared students' reading in electronic and paper dictionary conditions, they found no significant difference regarding the number of words searched, the search time, the rate of recall and the rate of recognition on the vocabulary test given a week after the reading session. One year later, in another study Koyama and Takeuchi (2004) conducted they found there is no necessarily corresponding effect on the higher look-up frequency encouraged by electronic dictionaries and the retention of the looked-up words. From lexical perspective, Kobayashi (2007) revealed that electronic dictionaries do not seem to have remarkable influence on students' vocabulary processing strategies, electronic dictionary group had a higher rate of consulting, at the same time paper dictionary group had a higher rate of inferring. There were also no big differences between these two groups in reading comprehension and word retention.

In contrast to the enthusiasm students have towards electronic dictionaries and see them as a preferable alternative to paper dictionaries, most EFL teachers seem to have a negative attitude towards electronic dictionaries, according to some researchers. In the 1990s, electronic dictionaries started to be paid attention to by teachers and researchers in the classroom. Taylor and Chan (1994) noticed that EFL 
teachers were quite questionable about the use of electronic dictionaries and they all prefer their students to consult paper dictionaries. Similar results were also found in Tang's (1997) research, Tang not only found negative perceptions of teachers towards electronic dictionaries, reasons were also analyzed from social and academic categories. From some teachers' point of view in Tang's research, electronic dictionaries can cause students' antisocial behaviors because instead of communicating with their classmates, students interact with machines in the classroom. Furthermore, when students play games and pass their electronic dictionaries around, it leads to great distraction to the whole class. In academic category, teachers are concerned about the quality of electronic dictionaries, such as artificial pronunciation, incorrect entry and incomplete entry. More importantly, a majority of teachers believe that electronic dictionaries cannot encourage students to learn through context. The learning process with electronic dictionaries is word-by-word translation. It cannot help students to improve their guessing and predicting skills and move away from words to sentences and discourse level. However, with the development of electronic dictionaries, researchers noticed changes on the part of teachers' attitudes towards electronic dictionaries. A definite move towards teachers' acceptance of electronic dictionary use in the classroom was found by Midlane (2005). Midlane conducted an online questionnaire survey on EFL/ESL teachers' attitude towards electronic dictionaries in 2005. This survey attracted 210 respondents worldwide. Most of them have more than 10 years' EFL/ESL teaching experience. It is also claimed by Midlane (2005) that the use of electronic dictionaries might be considered as an autonomous approach to EFL learning.

Some researchers are concerned that students may be over rely on electronic dictionaries (Nesi, 2003; Deng, 2006), especially when they had little judgement of the lexical content of their electronic dictionaries and were aware little of their disadvantages. As a result, it is claimed that teachers should give training or instructions on how to correctly use electronic dictionaries (Stirling, 2005; Bower \& McMillan, 2007; Kobayshi, 2008; Deng, 2006). Quite a few suggestions are given by researchers in their studies. Some suggestions given by Stirling (2005) include assigning students with electronic dictionary use related homework or in-class activities, conducting activities in which students can use different types of dictionaries and explore the advantages and disadvantages of electronic dictionaries. Bower and McMillan (2007) suggested some areas which might be beneficial to electronic dictionaries use and also when not to use them. At the same time, Midlane (2005) suggested that simply taking activities that designed for training students' use of paper dictionaries, and applying them with electronic dictionary users would make students ignore the differences between these two types of dictionaries and neglect the real advantages of electronic dictionary. Meanwhile, Midlane also pointed out that with bilingual electronic dictionaries, it was very difficult for teachers to tell their students how to evaluate electronic dictionaries and design specific activities for them; unless the EFL/ESL teachers share a common first language with their students. Just like one of the respondents in Midlane's research expressed this idea: "I feel many native English EFL teachers (at least) are unfairly negative about them. I think this is partly because we do not have access to them, we cannot easily/fairly 
evaluate them because we are generally not proficient in the two languages and because of our lack of familiarity".

Another argument is on the large amount of dictionary consolations and the fast search encouraged by electronic dictionaries. Tono (2000) pointed out that it is still not certain whether this frequent short-term access have long-lasting educational benefits for EFL students. Stirling (2005) pointed out that speed and ease of using electronic dictionaries may cause students' overuse and may be disadvantageous for vocabulary learning, although generally speaking, it is believed that looking up more words might be beneficial to vocabulary learning (Komuro et al., 2006, p. 133). In a study conducted by Guillot and Kenning (1993, pp. 72-73), they observed that electronic dictionaries encourage students to look up more unfamiliar words and "enabled students to leave no stone unturned, and gave them a degree of control over the materials, and momentum", and that lead to the reason why electronic dictionary can "generate its own learning impetus". However, the researchers admit in the study that if the fast speed of searching could be considered as an advantage of electronic dictionaries still questionable. According to Sharpe (1995, p. 50), with the help of electronic dictionaries, students only need a very short period of time to seek information. However, this may not improve the preservation of the information related to lexical acquisition for language learning purposes. It is stated that the decreased amount of time in the processing of looking up words may be disadvantageous to retention, that is, in Nesi's (2000a, p. 844) words, there is a "possibility that the most easily extracted information may require least thought, and be soonest forgotten". It has been actually proved by Laufer and Hill (2000, p. 72) that "the number of times the word is looked up during a learning session bears almost no relation to its retention". They conducted their research in both Hong Kong and Israel among 97 English as a Foreign Language (EFL) university learners. Participants were asked to read a text with 12 embedded low frequency words on the screen. While reading, they can look up any unknown word in an electronic dictionary built into a program. The program recorded every selection of dictionary information during the process. After reading, participants were unexpectedly asked to write the meanings of those target words either in their first language or in English. In that case, what truly determines to vocabulary retention is the focus of attention during the look up process but not the number of look-ups. In their following research, Laufer and Hulstijn (2001) found retention of new vocabulary is depend on the amount of involvement while processing these words. In other words, the deeper and more elaborate the involvement load, the better result of retention (Hulstijn \& Laufer, 2001, p. 545).

\section{Discussion}

In order for learners to enhance English learning efficiency and effectiveness, electronic dictionaries have been made available to language learners and used as mobile facilitators for language learning. The majority of electronic dictionaries students can purchase in the market are convenient and relatively inexpensive mobile tools (Liang et al., 2005). In today's Chinese EFL classrooms, it is 
normal to see students each armed with an electronic dictionary or smart phone, they swipe their fingers across the screen, consulting their electronic dictionaries to access new words and clarify difficult ideas. The popularity of electronic dictionaries demonstrate the tools' convenience in use compared to paper dictionaries beyond the boundaries of the traditional classroom environment.

Electronic dictionaries have advantages over paper dictionaries. Some of my colleagues believe it is necessary for students to own an electronic dictionary. Since they don't want to carry around a heavy paper dictionary, it is beneficial for student to have a small enough dictionary that they can carry in their pocket and have constant access to these important resources. Except easier to carry, electronic dictionaries are also better for class based activities because they won't occupy too much space and paper dictionary might be better for homework based tasks.

Besides, electronic dictionaries are very fast, limited class time can be used more efficient. When referencing a dictionary becomes an obstacle in a language class, the motivation for learning and study that language may be decreased. Electronic dictionaries can allow students not only to rapidly find necessary information about new words but also to quickly download the newest information about the vocabulary through online supplementary websites. The effort can be moved away from the laborious and repeated work of consulting the dictionary onto the actual language learning if students are permitted to use electronic dictionaries in class. Especially for beginners, they might come across a lot of new words when reading a text. Gradually, as a student's language efficiency level improve, the dependence on the dictionary declines because the student does not need to look up so many words and consequently the student may be more willingly to accept paper dictionaries. After all, while considering the present state of the electronic dictionary market, most electronic dictionaries that are affordable to EFL students in China are far from perfect. It is not a smart choice for students to rely only or too heavily on electronic dictionaries. They should not ignore another available language learning resource, that is, paper dictionaries.

Some teachers also believe the electronic dictionary use can allow them to present more challenging reading materials. Although, in my experience, teachers tend to pre-teach new and important vocabulary that students will come across in assigned reading materials, it is often difficult for teachers to anticipate every word that a student might have trouble with. Also, electronic dictionaries are usually user-friendly. Because of the linking to the Internet, in most of the cases they contain more words and expressions compare to paper dictionaries.

Nevertheless, some teachers believe electronic dictionaries to be noisy and distracting. Electronic dictionaries provide pronunciation and recording functions that can give learners an opportunity to hear spoken words and also practice speaking English. These days, it is common to see Chinese university students own smart phones which are equipped with software that supports using a nationwide popular dictionary app with lots of facilities such as speakers and headset. It is an attractive technological tool, but it can also have negative influence on students' English learning, especially during lessons. It can cause distraction to students and mixing its use with text messaging or Internet surfing for example. A 
lot of teachers complain that while students are using electronic dictionaries in class, especially dictionary apps in their mobile phones, they cannot really tell if a student is messaging a friend or looking for a word. That seems to become one major obstacle for teachers to be willingly to accept students using electronic dictionaries in class. They feel they are threatened by electronic dictionaries and might lose control of the class.

Others teachers who are in favor of paper dictionary state that there are paper dictionaries that are designed for language learners. A lot of them are published by publishers which have a history of compiling dictionaries and are regularly updated. However, electronic dictionaries are produced by technological companies which are not academic in nature. In some cases electronic dictionaries mislead students and give word to word translation in an odd way. Therefore, it is essential for teachers to offer EFL students with guidance on purchasing electronic dictionaries. They should give advices on how to choose and evaluate a reliable and proper electronic dictionary.

Another argument is that with the fast inputting speed, electronic dictionaries stop students thinking from the context and can cause a great distraction in the class. Some teachers noticed during in class activities that the moment students see a new word, they quickly resort to their electronic dictionaries for a translated meaning, that is, the Chinese equivalent, rather than sense making of the passage. Students' work sheets and comprehension passages are usually full of the Chinese equivalent of the vocabulary, squeezed between lines and in margins. We can easily see this from the learning of lower level EFL students because students are always worried about new vocabulary learning and they are not familiar with other techniques that can help them improve their language skills. Therefore, students are unlikely to learn words from the context, they tend to consider words as isolate but not related. They totally ignore the context in which the words exist. Instead, they check the meanings of every new word they come across. That causes students ignored the very important skill in language learning which is using the context to deduce the correct meanings. Moreover, the fast inputting speed can also hinder students learning the correct spelling of a word. Students may not always know how to spell a word correctly. Electronic dictionaries employ phonetic matching techniques and predictive text input techniques as spell checkers to help learners speed up access. Students might only need to type several letters instead of the whole word while they are looking it up in electronic dictionaries. That prevents them from learning the correct spelling during the process of vocabulary acquisition.

Some teachers can accept either a paper or electronic dictionary. They would be pleased to see students use a dictionary of any type rather than not bringing any. According to their opinions, if all information is there, it mainly depends on how accurate and comprehensive the dictionary is and it really doesn't matter which to use. It should be students' choice to decide to use either. At the same time they also emphasis that it is acceptable to let students use any type of dictionary as long as they do it under teacher's guidance. A lot of my students say that the reason that they select one particular type of electronic dictionary is usually based on personal preferences rather than pedagogical rationale. Alternatively, teachers could impose some control by giving advice on criteria for which types of 
electronic dictionaries are acceptable in class. Teachers can ask students to explore and compare the dictionary functions of the electronic dictionaries the students would like to buy in terms of lexicographical features and technological features. Under the guidance of teachers, students would easily choose to use electronic dictionaries properly for their level of language learning and activities conducted in the classroom. Actually in the field of teaching in science and engineering, the above approach has long been employed by teachers. Students are allowed to use certain models of pocket calculators appropriate for their level of study (Bitter \& Hatfield, 1993). Some of the other recommendations propose by them including: show students the differences between both types of dictionaries and train students on the use of them. At the same time, students should practice the use of dictionaries in regular class activities more frequently.

The use of electronic dictionaries in the classroom is a double-edged sword. In order to effectively engage modern students-so-called "digital natives", for whom mobile devices and the Internet are a way of life-EFL teachers feel we must integrate digital teaching strategies. Researches also indicate that electronic devices in the classroom have repeatedly shown to enhance engagement between teachers and students. At the same time, along with many modern electronic devices, electronic dictionaries are introduced into classroom and sometimes lead to student distraction and can even undermine learning. However, completely restricting electronic dictionaries isn't beneficial to EFL learning, either. Technology is so firmly fixed in modern society that the ignorance of its presence in the classroom only means students will be unprepared to face realities at the next level of learning or in their future careers. In a comprehensive 2012 report by the British National Endowment for Science, Technology and the Arts, the authors state that progressive thinking that is taken into account about technology use in the classroom means using it to support teaching and learning activities that teachers already know are effective. From my perspective, the use of electronic dictionaries can also follow this pattern. In the process of EFL learning, electronic may offer innovative and exciting ways for students to practice essential skills - already main constituents of EFL learning that can be reimagined through electronic dictionaries.

\section{Conclusion}

Discovering teaching and learning tools that save time and can contribute to learner achievement can help motivate teachers to learn more about effective uses of technology. As electronic dictionaries have become more and more attractive, accepted and popular to EFL learners at different levels, using electronic dictionaries in EFL classroom has gradually become an alternative to many. As a type of dictionary, it seems that the most significant role of electronic pocket dictionaries is to provide a widespread and fast alternative to paper dictionaries, in order to make sure that language learning activities in and outside the language learning classroom are facilitated. Nevertheless, considering both the advantages and disadvantages of electronic dictionaries, students must be taught learning strategies with the use of them. The traditional role of teachers as information gibers is changing. Teachers need 
to and are becoming facilitators, co-learners, and mentors. There are different ways for EFL/ESL teachers to learn about the use of electronic dictionaries in language teaching and learning. Thus, it is continuously hope that new study in the field will focus more on the actual usefulness of the electronic medium to dictionary users. The discovery or exploration phase will require the teacher to invest some time, but the eventual savings by having access to resources, information, models, and a community of learners in similar context can make the initial outlay well worth it.

\section{References}

Bax, S. (2003). CALL—Past, present and future. System, 31(1), 13-28.

Bitter, G. G., \& Hatfield, M. M. (1993). Integration of the math explorer calculator into the mathematics curriculum: The calculator project report. Journal of Computers in Mathematics and Science Teaching, 12, 59-81.

Boonmoh, A., \& Nesi, H. (2008). A Survey of Dictionary Use by Thai University Staff and Students, with Special Reference to Pocket Electronic Dictionaries. Horizontes de Lingüística Aplicada, 6(2), 79-90.

Bower, J., \& Brain, M. (2007). Learner's Use and Views of Portable Electronic Dictionaries. In K. Bradford-Watts (Ed.), JALT 2006 Conference Proceedings (pp. 697-708). Tokyo: JALT.

Castells, M. (2000). The Rise of the network society. The information age: Economy, society and culture (Vol. I). Cambridge, MA; Oxford: Blackwell.

Chen, Y. (2007). A Survey of English Dictionary Use by English Majors in Chinese Universities. Lexicographical Studies, 2, 120-130.

Deng, L. (2006). Survey of the Use of Paper Dictionaries and Electronic Dictionaries among College Students. Lexicographical Studies, 1, 172-181.

Deng, Y. P. (2005). A Survey of College Students' Skills and Strategies of Dictionary Use in English Learning. CELEA Journal, 28(4), 73-77.

Feng, L. (2007). An Investigation of Palmtop Electronic Dictionary Use. Bilingual Studies, 11, 57-59.

Gonzalez, O. (1999). Building vocabulary: Dictionary consultation and the ESL student. Journal of Adolescent and Adult Literacy, 43, 264-270.

Guillot, M.-N., \& Kenning, M.-M. (1994). Electronic Monolingual Dictionaries as Language Learning Aids: A Case Study. Computers in Education, 23, 63-73.

Hulstijn, J. H. M., \& Greidanus, T. (1996). Incidental vocabulary learning by advanced foreign language students: The influence of marginal glosses, dictionary use, and reoccurrence of unknown words. The Modern Language Journal, 80, 327-339.

Hulstijn, J. H., \& Laufer, B. (2001). Some Empirical Evidence for the Involvement Load Hypothesis in Vocabulary Acquisition. Language Learning, 51, 539-558.

Kent, D. (2001). Korean university freshmens' dictionary use and perceptions regarding dictionaries. The Korea TESOL Journal, 4, 73-92. 
Kobayashi, C. (2007). Comparing Electronic and Printed Dictionaries: Their Effects on Lexical Processing Strategy Use, Word Retention, and Reading Comprehension. In K. B. Watts (Ed.), JALT 2006 Conference Proceedings (pp. 657-671). Tokyo: JALT.

Kobayashi, C. (2008). The Use of Pocket Electronic and Printed Dictionaries: A Mixed-method Study. In K. B. Watts, T. Muller, \& M. Swanson (Eds.), JALT 2007 Conference Proceedings (pp. 769-783). Tokyo: JALT.

Komuro, Y., Shitara-Matsuo, Y., Ishii, Y., Uchida, S., Kawamura, A., \& Kanazashi, T. (2006). An Analysis of the Oxford Advanced Learner's Dictionary of Current English, Seventh Edition, with Special Reference to the CD-ROM. Lexicon, 36, 55-146.

Korat, O., \& Shamir, A. (2006). The educational electronic book as a tool for supporting children's emergent literacy in low versus middle SES groups. Computers \& Education, 50, 110-124.

Koyama, T., \& Osamu, T. (2003). Printed Dictionaries vs. Electronic Dictionaries: A Pilot Study on How Japanese EFL Learners Differ in Using Dictionaries. Language Education and Technology, 40, 61-79.

Koyama, T., \& Osamu, T. (2004). Comparing electronic and printed dictionaries: How the difference affected EFL learning. JACET Bulletin, 38, 33-46.

Lankshear, C., \& Knobel, M. (2003). New literacies: Changing knowledge and classroom learning. Buckingham \& Philadelphia: Open University Press.

Laufer, B., \& Hill, M. (2000). What Lexical Information do L2 Learners Select in a CALL Dictionary and How Does It Affect Word Retention? Language Learning and Technology, 3, 58-76.

Laufer, B., \& Hulstijn, J. H. (2001). Incidental Vocabulary Acquisition in a Second Language: The Construct of Task-Induced Involvement. Applied Linguistics, 22, 1-26.

Liang, J.-K., Liu, T.-C., Wang, H.-Y., Chang, B., Deng, Y.-C., \& Yang, J.-C. et al. (2005). A few design perspectives on one-on-one digital classroom environment. Journal of Computer Assisted Learning, 21(3), 181-189.

Liu, S. S.-C. (2007). Electronic dictionaries and ESL students. In Proceedings of International Conference on English Education. Shih Chien University, Taipei. Retrieved from http://www.usc.edu.tw/college/afl/data/\%E5\%8A\%89\%E6\%B7\%91\%E7\%85\%A7\%20(Electronic $\%$ 20Dictionaries\%20And\%20ESL\%20Students).pdf

Luppescu, S., \& Day, R. (1993). Reading dictionaries and vocabulary learning. Language Learning, 43, 263-287.

McAlpine, J., \& Myles, J. (2003). Capturing phraseology in an online dictionary for advanced users of English as a second language: A response to user needs. System, 31, 71-84.

Midlane, V. (2005). Students' Use of Portable Electronic Dictionaries in the EFL/ESL Classroom: A Survey of Teacher Attitudes. Manchester: University of Manchester, Faculty of Education.

Nesi, H. (2000). Electronic Dictionaries in Second Language Vocabulary Comprehension and Acquisition: The State of The Art. In U. Heid, S. Evert, E. Lehmann, \& C. Rohrer (Eds.), 
Proceedings of the Ninth Euralex International Congress, EURALEX 2000 (pp. 839-847). Stuttgart: Universita" t Stuttgart.

Nesi, H. (2003). The Virtual Vocabulary Notebook: The Electronic Dictionary as Vocabulary Learning Tool (pp. 10-12). Paper presented at the BALEAP conference. University of Southampton.

Park, M.-R. (2006). EFL college students' perceptions toward the use of electronic dictionaries. English Language \& Literature Teaching, 12, 29-54.

Perry, B. (2003). The use of pocket electronic dictionaries (PEDs) by Japanese university students. The Review of Liberal Arts, 105, 165-176.

Peters, E. (2007). Manipulating L2 Learners' Online Dictionary Use and Its Effect on L2 Word Retention. Language Learning and Technology, 11(2), 36-58.

Sharpe, P. (1995). Electronic Dictionaries with Particular Reference to the Design of an Electronic Bilingual Dictionary for English-Speaking Learners of Japanese. International Journal of Lexicography, 8, 39-54.

Stirling, J. (2005). The Portable Electronic Dictionary-Faithful Friend or Faceless Foe? Modern English Teacher, 14(3), 64-72.

Summers, D. (1988). The role of dictionaries in language learning. In R. Carter, \& M. McCarthy (Eds.), Vocabulary and Language Teaching (pp. 111-125). Longman, NewYork.

Tang, G. (1997). Pocket Electronic Dictionaries for Second Language Learning: Help or Hindance? TESL Canada Journal, 15(1), 39-57.

Taylor, A., \& Chan, A. (1994). Pocket Electronic Dictionaries and Their Use. In W. Martin et al. (Eds.), Proceedings of the 6th Euralex International Congress (pp. 598-605). Amsterdam: Vrije Universiteit.

Tono, Y. (2000). On the Effects of Different Types of Electronic Dictionary Interfaces on L2 Learners' Reference Behaviour in Productive/Receptive Tasks. In U. Heid, S. Evert, E. Lehmann, \& C. Rohrer (Eds.), Proceedings of the Ninth Euralex International Congress, EURALEX 2000 (pp. 855-861). Stuttgart: Universita“ t Stuttgart.

Wang, X. H. (2003). Palmtop Electronic Dictionary for Chinese EFL Students: Help or Hindrance? Teaching English in China, 26(1), 2-5.

Warschauer, M. (1999). Electronic literacies: Language, culture, and power in online education. Mahwah, NJ: Lawrence Erlbaum Associates.

Weschler, R., \& Pitts, C. (2000). An experiment using electronic dictionaries with EFL Students. The Internet TESL Journal, 6. Retrieved from http://www.iteslj.org/Articles/Weschler-ElectroDict.html 